- 研究报告・

\title{
黄河流域被子植物和陆栖脊椎动物 丰富度格局及其影响因子
}

\author{
孙远 胡维刚 姚树再 孙 颖 邓建明* \\ (兰州大学生命科学学院, 草地农业生态系统国家重点实验室, 兰州 730000)
}

\begin{abstract}
摘要: 生物多样性的大尺度空间分布格局及其形成机制一直是生态学和生物地理学的核心内容。黄河流域是我国 重要的生态屏障, 明确该区域动植物多样性分布格局及其影响因素, 对我国黄河流域生态保护和高质量发展具有 重要意义。本研究通过收集黄河流域被子植物和陆栖脊椎动物分布数据, 结合气候、环境异质性和人类活动等信 息, 探讨了黄河流域被子植物和陆栖脊椎动物物种丰富度格局及其主要影响因素。结果表明, 黄河流域被子植物 和陆栖脊椎动物物种丰富度在区域尺度具有相似的分布格局: 南部山地动植物物种丰富度最高, 而东部高寒区和 北部干旱区物种丰富度最低。回归树模型表明, 冠层高度范围和净初级生产力范围分别是黄河流域被子植物和陆 栖脊椎动物物种丰富度最重要的预测因子; 当移除空间自相关影响后, 环境异质性和气候因子依然对区域尺度的 动植物物种丰富度具有较高且相似的解释度。表明环境异质性和气候共同决定了黄河流域被子植物和陆栖脊椎动 物物种丰富度格局, 而人类使用土地面积并不是影响黄河流域动植物物种丰富度格局的主要因子。因此, 在未来 的研究中若针对不同区域篮选出更精准的环境驱动因子或选用更多不同类别的环境异质性因子进行分析, 将有助 于更深入理解物种多样性格局的成因。
\end{abstract}

关键词: 被子植物; 陆栖脊椎动物; 空间分布格局; 气候; 环境异质性; 黄河流域

\section{Geographic patterns and environmental determinants of angiosperm and terrestrial vertebrate species richness in the Yellow River basin}

\author{
Yuan Sun, Weigang Hu, Shuran Yao, Ying Sun, Jianming Deng* \\ School of Life Sciences, State Key Laboratory of Grassland Agro-Ecosystem, Lanzhou University, Lanzhou 730000
}

\begin{abstract}
Large-scale spatial distribution patterns of biodiversity and understanding the mechanisms that form these patterns are core questions for the fields of ecology and biogeography. The Yellow River basin is an important ecological barrier in China. Therefore, understanding the distribution patterns of plant and animal richness and what influences these patterns for is important for the ecological conservation and high-quality development of the Yellow River basin. Here, we used collected data for several variables (species spatial distribution, climate, environmental heterogeneity, and human activity) to explore the spatial distribution patterns of species richness and their main influencing factors for angiosperms and terrestrial vertebrates in the Yellow River basin. We found that the species richness for angiosperms and terrestrial vertebrates had similar distribution patterns at regional scale. Species richness was highest in the southern mountain region and lowest in the eastern alpine region and the northern arid region. Tree regression models showed that the canopy height range was the most important predictor for angiosperm species richness and net primary productivity range was the most important predictor for terrestrial vertebrate species richness. When the spatial autocorrelation was removed, environmental heterogeneity and climatic factors still had important and similar explanations for species richness at regional scale. The results indicate that species richness is determined by environmental heterogeneity and climate. Human activity was not a main influencing factor for species richness pattern. For future research, choosing more accurate environmental
\end{abstract}


driving factors for different regions or selecting different types of environmental heterogeneity factors for analyses will help with understanding the causes of species diversity patterns more deeply.

Key words: angiosperms; terrestrial vertebrates; spatial distribution patterns; climate; environmental heterogeneity; Yellow River basin

生物多样性的大尺度空间分布格局及其形成 机制一直是生态学和生物地理学的核心内容, 同时 也是实施生物多样性保护(比如优先保护区域的划 定等)必不可少的参考依据(Kerr \& Packer, 1997; Kreft \& Jetz, 2007; Jenkins et al, 2013)。想要探究生 物多样性的大尺度分布格局, 就必须先明确某个特 定区域内所有物种的实际分布范围。通常情况下, 动植物多样性的大尺度分布信息主要是通过检索 文献资料(包括动植物志书、图鉴等)、标本查阅以 及野外调查等方式获取。近年来, 我国已经开展了 大量的野外调查工作，比如“中国山地植物物种多 样性调查计划”等(方精云等, 2004)。但我国地域辽 阔、地形复杂, 是世界上生物多样性最丰富的 12 个 地区之一, 野外调查难度极大, 研究依然薄弱。

目前, 国内关于动植物多样性大尺度分布格局 的研究涉及诸多生物类群, 主要包括: 哺乳动物(林 金等, 2009; Xu et al, 2016)、鸟类(Zhao et al, 2006; 林金等, 2009)、两栖动物(Zhao et al, 2006)、爬行动 物(Xu et al, 2014)和维管植物(Wang et al, 2011; Li et al, 2013; Xu et al, 2016; Lu et al, 2018)等。同时, 国 内外学者也提出了不同的假说用于解释生物多样 性分布格局, 例如现代气候假说(Currie, 1991; O’Brien, 1998; O’Brien et al, 2000)、环境异质性假说 (Shmida \& Wilson, 1985; Kerr \& Packer, 1997; Stein et al, 2014)、历史成因假说(Ricklefs, 1987)以及人类 活动影响(Vitousek et al, 1997; Newbold et al, 2015) 等。这些假说并不互相排斥, 往往共同解释了生物 多样性的空间格局(Kreft \& Jetz, 2007)。然而, 目前 对于何种假说或者因子主要解释了生物多样性的 空间分布格局, 依然存在广泛争议。

毫无疑问, 生物多样性正面临着来自人类活动 导致的各方面压力, 例如生境退化或转变、直接采 挖或砍伐、环境污染以及气候变化等(Tittensor et al, 2014; 蒋志刚等, 2016)。然而, 人类活动对生物多样 性的影响在不同空间尺度上不尽相同。例如, 有研 究表明人类活动显著降低了局域生物多样性。
Newbold等(2015)通过量化局域生物多样性对土地 利用改变的响应发现, 在人类活动影响最严重的生 境中, 物种丰富度平均降低76.5\%, 总多度降低 $39.5 \%$ 。在区域尺度上，人类活动如何影响生物多样 性仍缺乏一致的结论。比如, 有研究表明, 人类活 动对我国木本植物和陆栖脊椎动物物种丰富度仅 具有很微弱的影响(Wang et al, 2011; Xu et al, 2014); 人口密度与不同类群物种丰富度之间存在正相关 关系(Luck, 2007)。

黄河是我国第二大河, 发源于青海省巴颜喀拉 山，流经青海、四川、甘肃、宁夏、内蒙古、陕西、 山西、河南和山东 9 个省(区)。黄河干流通常以内 蒙古的河口镇和河南郑州的桃花峪为分界点, 划分 为上、中、下游。黄河流域内地势西高东低, 高差 悬殊，形成自西而东、由高及低的三级阶梯，总面 积约为 79.5 万 $\mathrm{km}^{2}$, 涵盖南温带、中温带和高原气 候区, 属于干旱、半干旱和半湿润地带, 主要植被 类型包括荒漠、草原、灌木、森林等。黄河流域是 我国重要的生态屏障, 其生态保护与高质量发展已 上升为重大国家战略, 研究该区域生物多样性分布 格局及其形成机制具有重要意义。到目前为止，我 国生物多样性的大尺度格局及其形成机制的研究 大多在全国或省级尺度上进行, 缺乏专门针对黄河 流域的区域尺度研究。全国尺度的研究表明，黄河 流域动植物多样性普遍较低(林鍂等, 2009; Xu et al, 2016; Lu et al, 2018), 但其影响因素仍不明确。

鉴于此，本文以黄河流经的 66 个地市(州、盟) 为研究区域(总面积约为 160 万 $\mathrm{km}^{2}$ ), 根据相关地理 位置进一步将其划分为上游、中游和下游(图 1), 通 过收集被子植物和陆栖脊椎动物(主要包括哺乳动 物、两栖动物和鸟类)物种分布数据, 结合气候、环 境异质性和人类活动(人类使用土地面积)等信息， 初步探讨了黄河流域动植物物种多样性格局及其 成因。在气候变化和人类活动不断加剧的背景下, 本研究将为维持该区域生态安全和高质量发展提 供基础数据与理论依据。 


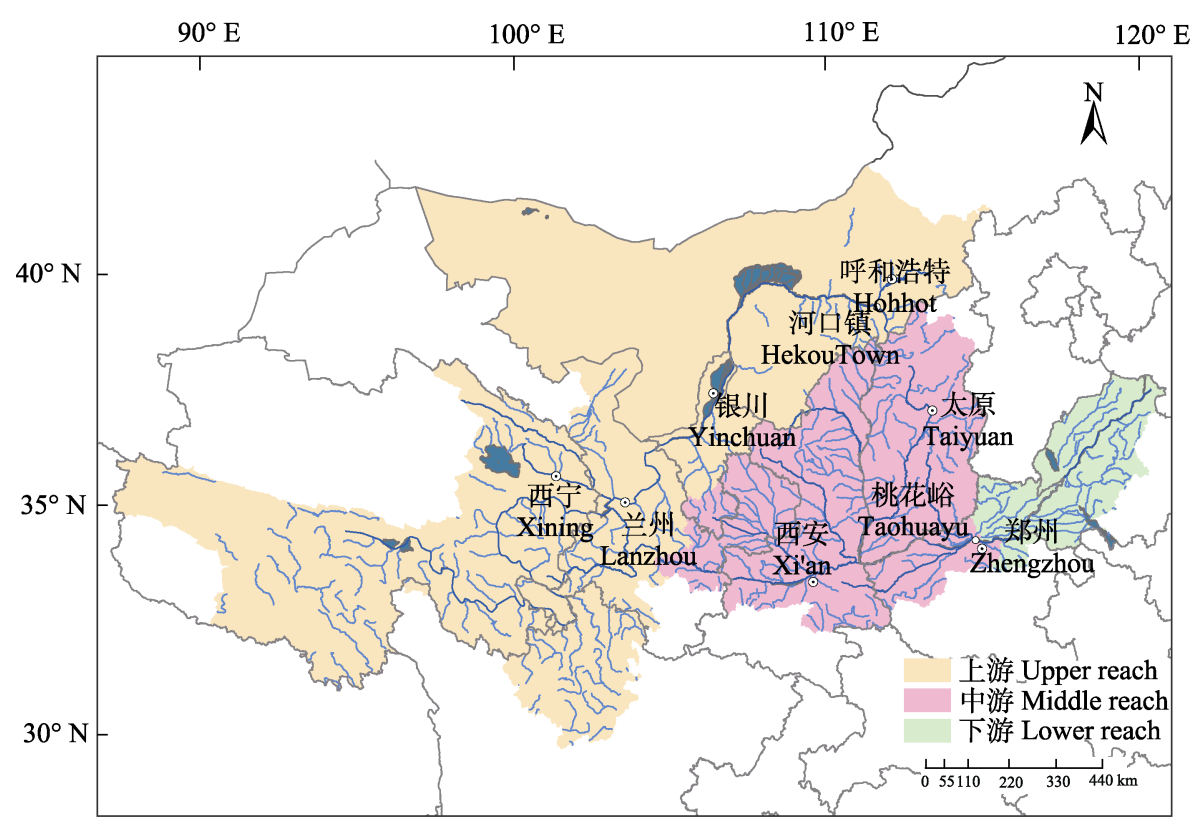

图1 黄河流域地市(州、盟)位置示意图

Fig. 1 Location of the cities (prefecture or league) involved in the Yellow River basin

\section{1 材料和方法}

\section{1 物种分布数据}

本研究中被子植物分布数据主要来源于 $\mathrm{Lu}$ 等 (2018), 哺乳动物和两栖动物分布数据来源于国际 自然保护联盟(Union for Conservation of Nature, IUCN; www.iucn.org), 鸟类分布数据来源于国际鸟 盟(Birdlife International; www.birdlife.org)。本文定 义的黄河流域范围为黄河干流及其支流所流经的 所有地级行政区, 黄河流域边界数据来源于国家地 球系统科学数据中心(http://www.geodata.cn/), 中国 地图和地市行政边界数据来源于中国科学院资源 环境科学数据中心(http://www.resdc.cn)。为了消除 调查面积对物种丰富度的影响, 将黄河流域边界范 围图层在ArcGIS 10.5中重采样为 $100 \mathrm{~km} \times 100 \mathrm{~km}$ 的 等面积栅格, 共得到222个栅格, 同时去除面积小 于 $4,000 \mathrm{~km}^{2}$ 的栅格, 最后统计单个栅格内出现的物 种数量。

\section{2 环境因子数据}

为了分析环境因子对黄河流域动植物多样性 格局的影响, 本文使用了4类共11个环境预测变量 (表1)。包括: (1)气候因子, 包括年平均温度(mean annual temperature, TEM)、年降水量(mean annual precipitation, PRE)、温度季节性 (temperature seasonality, TSN) 和降水季节性 (precipitation seasonality, PSN); (2) 净初级生产力 (net primary productivity, NPP); (3)环境异质性因子(各因子在单 个栅格内的跨幅), 包括温度范围(temperature range, TEM.ra)、降水范围(precipitation range, PRE.ra)、海 拔范围 (elevation range, ELE.ra)、NPP范围(NPP range, NPP.ra)和冠层高度范围 (vegetation height range, HEI.ra); (4)人类使用土地面积(human used areas, HUA)。在构建模型前, 使用方差膨胀因子 (variance inflation factors, VIF) 和Pearson相关系数检 测预测因子之间的共线性, 发现 NPP和 NPP.ra、 TEM.ra和ELEV.ra之间具有强烈的共线性(VIF $>10)$ 。 为了最小化共线性的影响, 去除了 NPP和TEM.ra, 使得所有变量的VIF值都小于10且变量之间的相关 系数小于 0.85 。

以上环境数据中, 气候数据来自于WorldClim 数据库(Hijmans et al, 2005), 图2a、2b分别表示黄河 流域年均温和年降水量的分布图。海拔地形数据来 源于美国地质调查局(United States Geological Survey, USGS)的数字高程模型(Digital Elevation Model, DEM) (https://lta.cr.usgs.gov/GTOPO30; 图 2c)。净初级生产力数据来自于蒙大拿大学的美国航 空航天局(National Aeronautics and Space Administration, NASA)对地观测系列卫星(Earth Observing 
表1 黄河流域被子植物和陆栖脊椎动物丰富度以及各环境变量的基本统计信息

Table 1 Descriptive statistics of species richness and environmental variables in the Yellow River basin

\begin{tabular}{|c|c|c|c|}
\hline & $\begin{array}{l}\text { 最小值 } \\
\text { Min. }\end{array}$ & $\begin{array}{l}\text { 最大值 } \\
\text { Max. }\end{array}$ & $\begin{array}{l}\text { 平均值 } \\
\text { Mean }\end{array}$ \\
\hline \multicolumn{4}{|l|}{ 物种丰富度 Species richness } \\
\hline 被子植物 Angiosperms & 279 & 5,076 & 1,301 \\
\hline 陆栖脊椎动物 Terrestrial vertebrates & 81 & 528 & 232 \\
\hline \multicolumn{4}{|l|}{ 环境因子 Environmental variables } \\
\hline 人类使用土地面积 Human used areas (HUA, km²) & 0.00 & $9,967.42$ & 2,337.76 \\
\hline 年均温 Mean annual temperature $\left(\mathrm{TEM},{ }^{\circ} \mathrm{C}\right)$ & -7.50 & 14.53 & 5.04 \\
\hline 温度季节性 Temperature seasonality (TSN, ${ }^{\circ} \mathrm{C}$ ) & 6.01 & 13.63 & 9.70 \\
\hline 年降水量 Annual precipitation (PRE, mm) & 36.04 & 979.78 & 404.99 \\
\hline 降水季节性 Precipitation seasonality (PSN, mm) & 68.62 & 117.98 & 95.84 \\
\hline 净初级生产力 Net primary productivity (NPP, gC/m²) & 0.22 & 674.55 & 207.16 \\
\hline 温度范围 Temperature range (TEM.ra, ${ }^{\circ} \mathrm{C}$ ) & 0.60 & 23.70 & 7.61 \\
\hline 降水范围 Precipitation range (PRE.ra, mm) & 17.00 & 523.00 & 174.28 \\
\hline 海拔范围 Elevation range (ELE.ra, m) & 33.00 & $5,048.00$ & $1,356.22$ \\
\hline 净初级生产力范围 Net primary productivity range (NPP.ra, gC/m²) & 1.20 & $1,274.60$ & 397.63 \\
\hline 冠层高度范围 Canopy height range (HEI.ra, m) & 3.00 & 43.00 & 24.05 \\
\hline
\end{tabular}

Satellites，EOS) 项 目 (http://www.ntsg.umt.edu/ project/modis/mod17.php; 图2d)。冠层高度数据来自 全球森林冠层高度数据(Simard et al, 2011; 图2e)。 以上数据空间分辨率约为 $1 \mathrm{~km} \times 1 \mathrm{~km}$ 。人类活动数 据来源于全国地理信息资源目录服务系统平台的 GlobeLa-nd30 数 据 集 (http://www.webmap.cn/ mapDataAction. do?method=globalLandCover; 图2f), 空间分辨率为 $30 \mathrm{~m} \times 30 \mathrm{~m}$, 一个栅格里面的人类使 用土地面积为人造表面和耕地面积的总和。

\section{3 统计分析}

使用多元回归树(multivariate regression trees, MRT; De’Ath \& Fabricius, 2000)和多元线性回归模 型分析物种丰富度与预测变量之间的关系。

回归树的构建包括两个过程: 一是树的构建。 即采用二元递归分解法。回归树每次都选择当前数 据集中具有最小Gini信息增益的特征作为节点, 将 数据集分解到不同子集当中。二是树的修剪。以上 过程产生的树往往比较大, 对训练集很可能过度拟 合。采用1-SE规则(De'Ath et al, 2002)对树进行修剪, 即与具有最小交叉验证相对误差(cross-validated relative error)的树之间的差异小于 1 个标准误且分 裂次数更少的树视为最优树。我们分别将被子植物 物种丰富度和陆栖脊椎动物物种丰富度作为响应 变量, 相应的环境因子作为预测变量(表1), 建立多
元回归树模型。

多元线性回归采用最小二乘法(ordinary least squares, OLS)进行拟合，同样分别将动植物物种丰 富度作为因变量, 上述环境因子作为自变量进行分 析(表1)。需要说明的是，鉴于被子植物物种丰富度 会影响陆栖脊椎动物物种丰富度，当使用多元线性 回归分析动物物种丰富度与预测变量关系时，将被 子植物物种丰富度作为预测变量之一进行拟合。物 种丰富度数据通常呈现非正态分布，为了避免数据 分布的偏态对统计分析带来的影响，在进行多元回 归分析前, 将动植物物种丰富度数据进行对数( $\log )$ 转换; 同时为了使模型系数可以比较, 也将所有环 境因子进行 $Z$ 分数标准化处理。最优线性回归模型 使用 R语言中的step()函数并结合赤池信息量准则 (Akaike Information Criterion, AIC)来确定(Burnhan \& Anderson, 2002)。由于空间自相关性会影响回归 模型的解释力, 使用Moran's I方法评估多元回归模 型残差的空间自相关性。由于多元回归模型的残差 具有显著的空间自相关性 $(P<0.05)$, 进一步使用最 优模型中的预测变量建立空间自回归模型(spatial linear simultaneous autoregressive error model, SAR)。 使用Pseudo- $R^{2}$ (非空间成分的模型预测值和实际值 之间的相关系数的平方)来衡量预测变量对物种丰 富度的解释能力(Kissling \& Carl, 2008), 并通过偏 

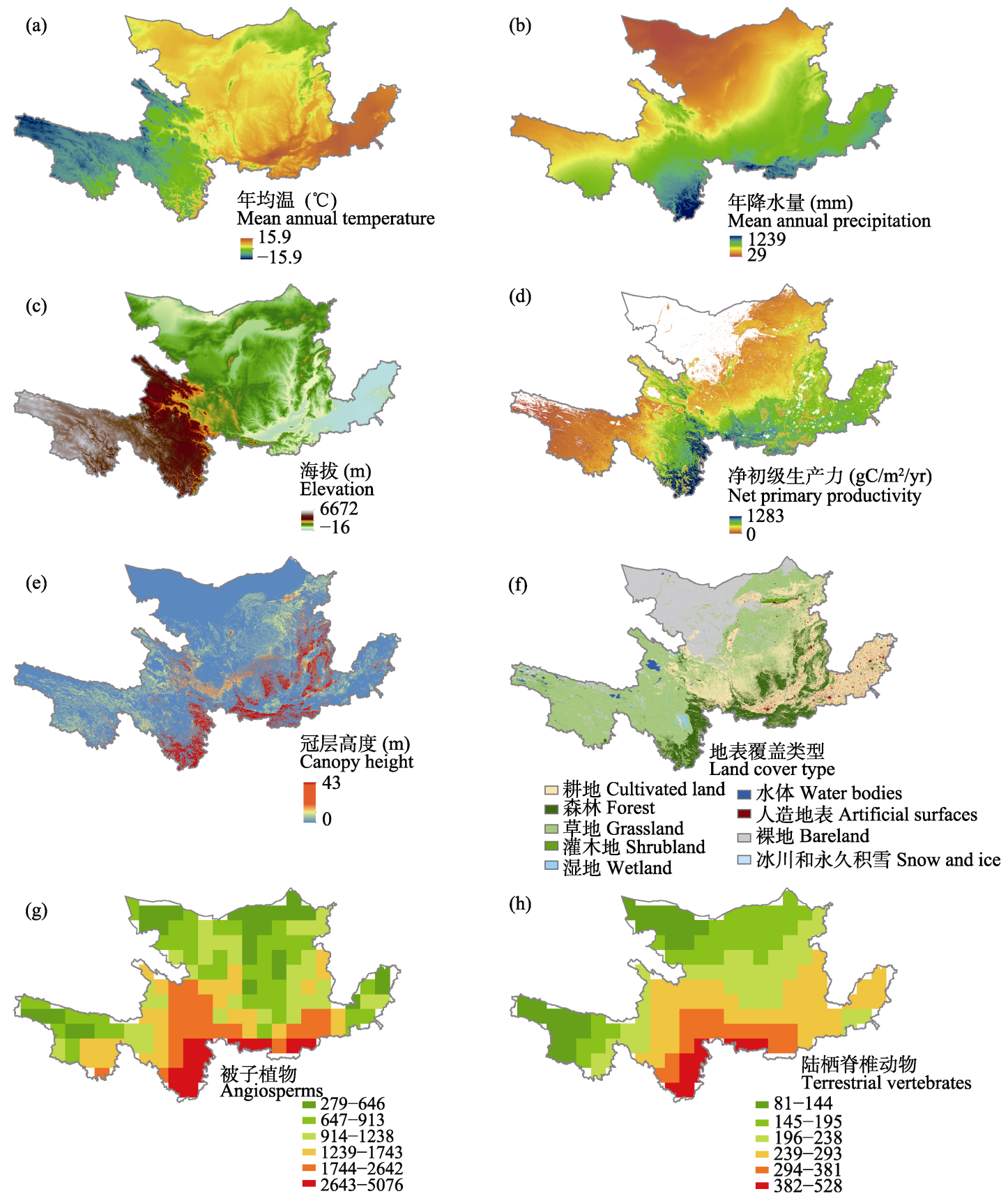

图2 黄河流域环境变量分布图以及被子植物和陆栖脊椎动物物种丰富度的空间格局

Fig. 2 Distribution of environmental variables and spatial pattern of species richness of angiosperms and terrestrial vertebrates in the Yellow River basin

回归系数比较预测变量间的相对重要性。

本文的统计分析在 R 3.6.1 (R Development Core Team, 2019)中进行, 其中, 多元回归树模型和 空间自回归模型模型分别利用使用 $\mathrm{R}$ 语言中的 rpart 程序包和 spdep 程序包中的相关代码进行。

\section{2 结果}

图 $2 \mathrm{~g}$ 和图 $2 \mathrm{~h}$ 显示, 黄河流域动植物物种丰富
度均呈现明显的地区差异。黄河流域南部地区动植 物物种最为丰富, 主要为四川阿坝藏族自治州以及 陕西南部靠近秦岭一带; 流域上游的青海省东部、 甘肃省大部分区域动植物物种丰富度也较高。流域 东部的玉树藏族自治州东北部区域, 北部的阿拉 善、鄂尔多斯等内蒙古西部区域以及流域中部的陕 西北部区域是动植物物种丰富度最贫乏的地区; 流 域下游的华北平原被子植物丰富度也较低, 陆栖冷 
椎动物物种丰富度呈中等水平。

在使用被子植物和陆栖脊椎动物数据构建回 归树时, 都只有 9 个变量中的 5 个被使用(图3)。对被 子植物而言, 回归树包含 8 个分支, 解释了物种丰 富度总变异的 $86 \%$ 。其中, 最重要的影响因子是冠 层高度范围。回归树第一个节点以冠层高度范围 (33 m) 为界分为两支, 解释了总变异的 $50 \%$ 。冠层高
度范围大于 $33 \mathrm{~m}$ 的区域为高物种丰富度区域，该区 域内, 海拔范围是影响被子植物物种丰富度格局的 最重要因子，解释了总变异的 $18 \%$ 。冠层高度大于 $33 \mathrm{~m}$ 且海拔范围大于 $3,005 \mathrm{~m}$ 的区域，拥有黄河流 域最高的被子植物物种丰富度，平均为3,841个种。 相反, 冠层高度范围小于 $33 \mathrm{~m}$ 的区域具有较低或中 等水平的被子植物多样性，该区域内，被子植物物

(a)

\section{1}

$n=171$

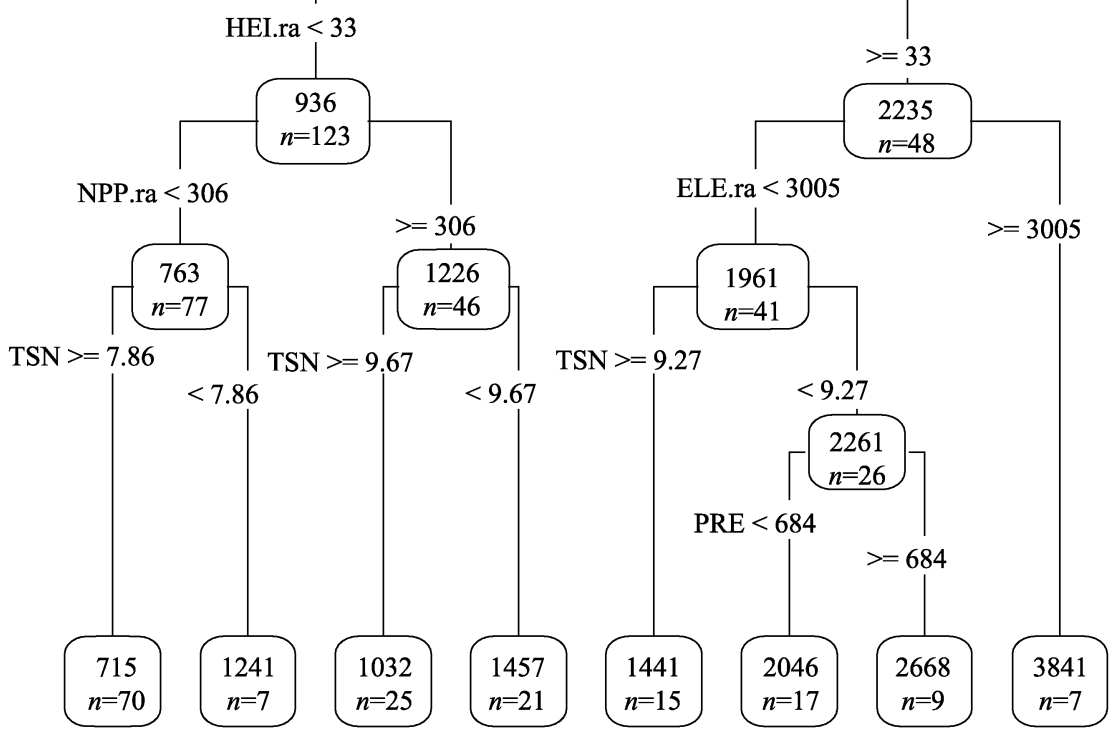

(b)

232

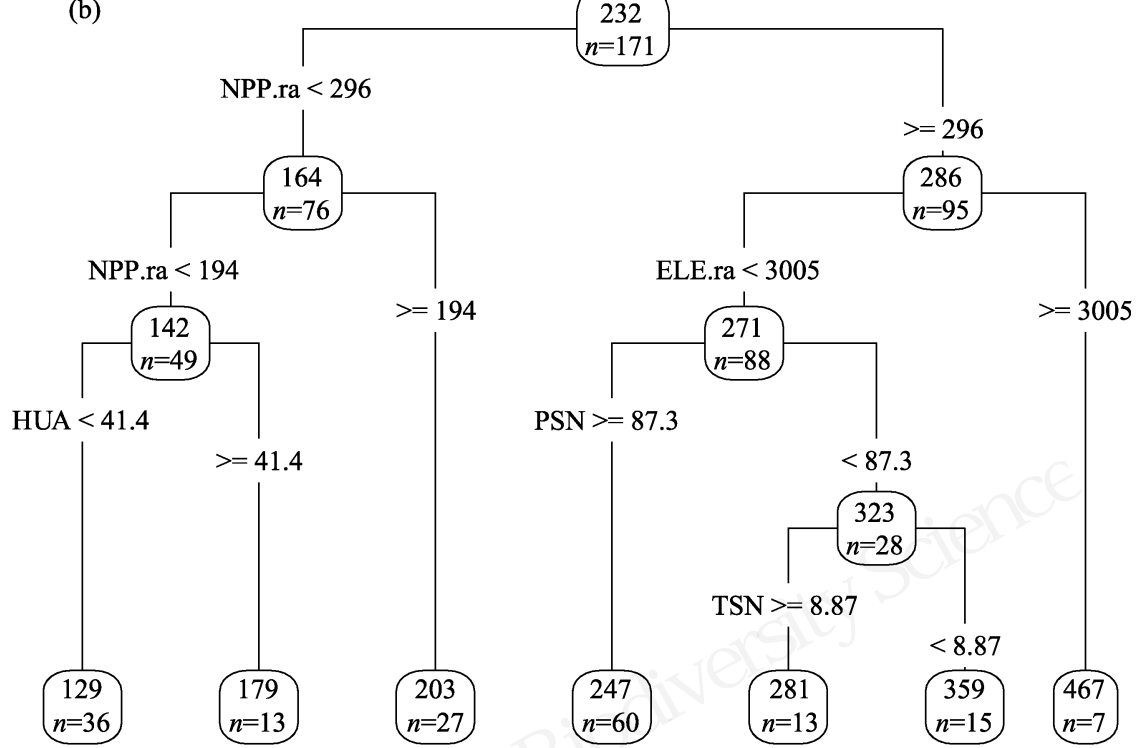

图3 黄河流域被子植物(a)和陆栖脊椎动物(b)物种丰富度的回归树分析。HEI.ra: 冠层高度范围; NPP.ra: 净初级生产力范 围; TSN: 温度季节性; ELE.ra: 海拔范围; PRE: 年降水量; HUA：人类使用土地面积; PSN：降水季节性。

Fig. 3 Regression tree analysis of species richness of angiosperms (a) and terrestrial vertebrates (b) HEI.ra, Vegetation height range; NPP.ra, Net primary productivity range; TSN, Temperature seasonality; ELE.ra, Elevation range; PRE, Mean annual precipitation; HUA, Human used areas; PSN, Precipitation seasonality. 
种丰富度与 NPP范围呈正相关关系; 以 NPP范围 $\left(306 \mathrm{gC} / \mathrm{m}^{2}\right)$ 为界, 回归树被进一步分为两支, 温度 季节性在这两支中均与被子植物物种丰富度呈负 相关。这些节点单独只能解释 $<6 \%$ 的总变异。对陆 栖脊椎动物而言, 回归树模型解释了物种丰富度总 变异的 $92 \%$ 。其中, NPP范围是最重要的影响因子, 解释了总变异的 $52 \%$; 其次为海拔范围, 解释了总变 异的20\%。与被子植物一致，海拔范围大于 $3,005 \mathrm{~m}$ 的区域拥有最高的陆栖脊椎动物物种丰富度。

多元回归模型分别解释了被子植物和陆栖脊 椎动物物种丰富度总变异的79\%和 $87 \%$ 。由于空间 自回归(SAR)模型去除了空间自相关的影响, 解释 度有所降低, 分别为 $62 \%$ 和 $69 \%$ 。由表2得出, 各变 量在解释动植物物种丰富度格局中的重要性在不 同回归模型间有所差异。对于被子植物物种丰富度 而言, 多元回归模型显示, 降水季节性与海拔范围 是最重要的预测因子，而空间自回归模型表明除了 上述两个因子外，温度季节性和冠层高度范围也同 等重要。在多元回归和空间自回归模型中, 被子植 物物种丰富度与海拔范围和冠层高度范围均呈正

表2 被子植物和陆栖脊椎动物物种丰富度的多元线性回归 和空间自回归(SAR)模型分析结果

Table 2 Results of ordinary least squares (OLS) and simultaneous autoregressive (SAR) models for species richness of angiosperms and terrestrial vertebrates

\begin{tabular}{|c|c|c|c|c|}
\hline \multirow[t]{2}{*}{ 预测因子 Predictor } & \multicolumn{2}{|c|}{$\begin{array}{l}\text { 被子植物 } \\
\text { Angiosperms }\end{array}$} & \multicolumn{2}{|c|}{$\begin{array}{l}\text { 陆栖脊椎动物 } \\
\text { Terrestrial vertebrates }\end{array}$} \\
\hline & coef $_{\text {oLs }}$ & $\operatorname{coef}_{\mathrm{SAR}}$ & coefols & coeff $_{\mathrm{SAR}}$ \\
\hline $\begin{array}{l}\text { 人类使用土地面积 } \\
\text { (HUA) }\end{array}$ & - & - & - & - \\
\hline 年均温 (TEM) & - & - & $0.05^{* *}$ & $0.09^{* * *}$ \\
\hline 温度季节性 (TSN) & $-0.09 * *$ & $-0.13^{*}$ & $0.07^{*}$ & $-0.14^{* * *}$ \\
\hline 年降水量 (PRE) & - & & $0.11^{* * *}$ & 0.04 \\
\hline 降水季节性 (PSN) & $-0.17 * * *$ & $-0.13^{* *}$ & $-0.04 *$ & 0 \\
\hline 净初级生产力 (NPP) & - & - & - & - \\
\hline 降水范围 (PRE.ra) & 0.05 & $0.07^{*}$ & 0.02 & $0.02^{* * *}$ \\
\hline 海拔范围 (ELE.ra) & $0.15^{* * *}$ & $0.11^{* *}$ & - & - \\
\hline $\begin{array}{l}\text { 净初级生产力范围 } \\
\text { (NPP.ra) }\end{array}$ & $0.09 *$ & 0.03 & $0.17^{* * *}$ & 0.01 \\
\hline 冠层高度范围 (HEI.ra) & 0.07 & $0.12^{* *}$ & - & 0.04 \\
\hline 被子植物丰富度 (Plant) & - & - & $0.11^{* *}$ & $0.04^{*}$ \\
\hline AIC & 28.58 & -26.79 & -200.12 & -515.81 \\
\hline$R^{2}$ & 0.79 & 0.62 & 0.87 & 0.69 \\
\hline
\end{tabular}

预测因子缩写的含义同表 1 Abbreviations of the predictors correspond to those in Table 1. ${ }^{*} P<0.05$; ${ }^{* *} P<0.01$; ${ }^{* * *} P<0.001$.
相关，而与降水季节性和温度季节性均呈负相关。 该结果表明, 在气候季节性变化小且环境异质性高 的区域被子植物物种丰富度较高。对于陆栖脊椎动 物物种丰富度而言, 多元回归模型显示, NPP 范围 是其最重要的影响因子，其次是年均降水量和被子 植物物种丰富度; 而空间自回归模型表明，其最重 要的影响因子为温度季节性, 其次为年均温。因此, 不同统计模型在确定黄河流域脊椎动物物种丰富 度最佳预测因子方面还存在较大的不确定性。总体 而言，不同模型间各环境变量在解释动植物物种丰 富度格局时有所差异，回归树模型表明环境异质性 对动植物多样性格局具有重要影响, 而线性回归模 型则表明气候因子与环境异质性同等重要。

\section{3 讨论}

黄河流域生物多样性最丰富的区域主要集中 在山地, 比如青藏高原东部山区、陕西省南部秦岭 山区以及四川省北部岷山和邛崃山区。这与之前在 不同空间尺度上得到的结果一致。比如 Li 等(2013) 研究了新疆维管植物和哺乳动物的空间分布格局, 发现维管植物物种丰富度最高的区域是阿尔泰山 西部以及天山中西部, 山区哺乳动物物种丰富度也 高于盆地; 在全国尺度上，山区的维管植物和哺乳 动物物种丰富度同样高于周边区域, 包括我国动植 物物种最为丰富的横断山脉、秦岭、喜马拉雅东南 部等地区(Xu et al, 2016)。此外, 全球34个生物多样 性热点区域中的大部分也都位于山地(http://www.

biodiversityhotspots.org)。这主要是因为山地具有较 大的海拔高差, 覆盖了多样的地质、地形和气候梯 度, 因此较高的环境异质性使得山地比周边低地拥 有更高的生物多样性(Becker et al, 2007; Moeslund et al, 2013)。

尽管对于生物多样性大尺度格局的形成机制 存在诸多解释, 但大多研究认为当代气候是生物多 样性最重要的影响因素。比如Wang等(2011)通过研 究中国木本植物分布格局发现, 最冷季温度是预测 木本植物丰富度最重要的因子。Qian (2013)发现温 度季节性变化是中国木本植物物种丰富度的最佳 预测因子。Kreft和Jetz (2007)通过对全球维管植物 的研究发现, 植物物种丰富度的地理格局受多个环 境因子的共同影响，但与潜在蒸散量 (potential evapotranspiration, PET)和湿润天数(wet days)相关 
的气候因子起主导作用。本研究中回归树模型显示, 环境异质性是被子植物和陆栖脊椎动物物种丰富 度最重要的预测变量。环境异质性高的区域, 动植 物物种丰富度也高。比如冠层高度范围大于 $33 \mathrm{~m}$ 的 区域(主要为山地)的被子植物物种丰富度(平均值 为2,235种)远大于其他区域(平均值为936种)。此外, 空间自回归模型表明, 环境异质性和气候变量对被 子植物和陆栖脊椎动物物种丰富度具有相似的解 释度(表2)。这些结果说明环境异质性和气候是影响 黄河流域被子植物和陆栖脊椎动物多样性的重要 因素，并共同决定了其大尺度分布格局。

环境异质性可以通过3种主要机制影响生物多 样性：(1)环境异质性高的区域拥有更多样的栖息地 类型和更丰富的可利用资源, 进而通过提供更多的 生态位促进物种共存(Currie, 1991); (2)环境异质性 高的区域在环境条件不利时为生物群落提供了避 难所，从而降低了种群灭绝的风险(Svenning \& Skov, 2007); (3)高环境异质性通过生境隔离或生理 生态适应增加了物种分化的可能性 (Hughes \& Eastwood, 2006; Xing \& Ree, 2017)。对环境异质性 的定量计算方式有很多种, 主要包括环境因子的范 围(比如海拔范围)、标准差(SD)、变异系数 $(C V)$ 以 及指数等。不同的环境异质性度量包含不同的信息, 反应了环境异质性对生物多样性的不同影响机制 (Stein \& Kreft, 2015)。本研究主要使用了单个网格 内各环境因子的变化范围来度量环境异质性, 主要 反映了该区域内环境梯度的宽幅, 且与生态位的宽 度直接相关。因此, 本研究发现的环境异质性与动 植物物种丰富度之间的正相关关系表明了环境异 质性通过提供更多的生态位促进该区域物种的共 存。然而, 环境异质性对物种丰富度格局的影响往 往具有区域地理或气候依赖性(Xu et al, 2016; Kerr et al, 2017), 环境异质性更可能在可利用能量高的 区域占主导地位。例如Kerr等(1997)发现在北美潜 在蒸散量大于 $1,000 \mathrm{~mm}$ 的高热量区域, 环境异质性 是影响哺乳动物丰富度地理分异的主要因素。Xu 等(2016)发现在中国海拔低于 $1,900 \mathrm{~m}$ 的区域, 海拔 是影响维管植物空间分布的主要因子。

与局域尺度相比, 人类活动在区域尺度上对物 种丰富度的影响仍具有较大的不确定性。黄河中游 的黄土高原以及下游的华北平原具有广阔的耕地 分布(图2e), 黄河上游的青藏高原是过度放牧的区
域, 生境退化或丧失以及直接采挖或砍伐往往是影 响生物多样性的重要因素(蒋志刚等, 2016)。由于 特 定区域内耕地和城镇建设用地等人为活动的扩张, 动植物生境逐步减少, 种群数量与物种丰富度下降, 加之人类活动导致的生境同质化也会降低生物群 落间的 $\beta$ 多样性，最终该区域的 $\gamma$ 多样性将受到抑制 (Newbold et al, 2015)。然而, 本研究结果显示, 人类 活动并不是影响区域尺度动植物物种丰富度格局 的主要因子，人类土地使用面积仅在NPP范围小于 $194 \mathrm{~g} \mathrm{C} / \mathrm{m}^{2}$ 的区域内与陆栖脊椎动物物种丰富度呈 正相关关系(图3)。这一结果与Wang等(2011)对中国 木本植物和Xu等(2014)对中国脊椎动物多样性格局 的研究结果一致, 可能的原因是人类活动对动植物 物种丰富度空间变异的解释度受研究区域空间尺 度的影响(Sarr et al, 2005; Wang et al, 2011)。也可能 是由于人类活动涉及众多方面, 很多都难以量化, 而选用的表征人类活动的因子，比如国内生产总值 和人口密度(Wang et al, 2011)等, 并不能很好地代 表全部人类活动。因此，在区域尺度上，人类活动 对物种丰富度格局的影响仍有待进一步研究。

基于回归树模型和线性回归模型的分析结果, 表明现代气候因子和环境异质性对黄河流域动植 物物种多样性格局均具有重要影响。该研究结果表 明在未来的自然保护尤其生物多样性保护的规划 与执行过程中, 需要科学地考虑和利用环境异质性 对生物多样性的影响。不过, 在未来的研究中若针 对不同区域篎选出更精准的环境驱动因子或选用 更多不同类别的环境异质性因子进行分析，将有助 于更深入理解物种多样性格局的成因。虽然我们的 结果并没有发现人类活动对物种丰富度格局的直 接影响, 但人类活动依然有可能通过影响未来气候 并加速生境同质化等, 间接对物种多样性造成重要 的负面影响。

\section{参考文献}

Becker A, Körner C, Brun JJ, Guisan A, Tappeiner U (2007) Ecological and land use studies along elevational gradients. Mountain Research and Development, 27, 58-65.

Burnhan KP, Anderson DR (2002) Model selection and multi-model inference: A practical information-theoretic approach. Technometrics, 45, 181-181.

Currie DJ (1991) Energy and large-scale patterns of animaland plant-species richness. The American Naturalist, 137, 27-49. 
De’Ath G (2002) Multivariate regression trees: A new technique for modeling species-environment relationships. Ecology, 83, 1105-1117.

De’Ath G, Fabricius KE (2000) Classification and regression trees: A powerful yet simple technique for ecological data analysis. Ecology, 81, 3178-3192.

Dong XR, Zhang H, Zhang MG (2019) Explaining the diversity and endemic patterns based on phylogenetic approach for woody plants of the Loess Plateau. Biodiversity Science, 27, 1269-1278. (in Chinese with English abstract) [董雪芯, 张 红, 张明罡 (2019) 基于系统发育的黄土高原地区木本 植物多样性及特有性格局. 生物多样性, 27, 1269-1278.]

Fang JY, Shen ZH, Tang ZY, Wang ZH (2004) The protocol for the survey plan for plant species diversity of China's mountains. Biodiversity Science, 12, 59. (in Chinese with English abstract) [方精云, 沈泽吴, 唐志尧, 王志恒 (2004) “中国山地植物物种多样性调查计划” 及若干技术 规范. 生物多样性, 12, 5-9.]

Hijmans RJ, Cameron SE, Parra JL, Jones PG, Jarvis A (2005) Very high resolution interpolated climate surfaces for global land areas. International Journal of Climatology, 25, 1965-1978.

Hughes C, Eastwood R (2006) Island radiation on a continental scale: Exceptional rates of plant diversification after uplift of the Andes. Proceedings of the National Academy of Sciences, USA, 103, 10334-10339.

Jenkins CN, Pimm SL, Joppa LN (2013) Global patterns of terrestrial vertebrate diversity and conservation. Proceedings of the National Academy of Sciences, USA, 110, E2602-E2610.

Jiang ZG, Li LL, Luo ZH, Tang SH, Li CW, Hu HJ, Ma Y, Wu Y, Wang YX, Zhou KY, Liu SY, Feng ZJ, Cai L, Zang CX, Zeng Y, Meng ZB, Ping XG, Fang HX (2016) Evaluating the status of China's mammals and analyzing their causes of endangerment through the red list assessment. Biodiversity Science, 24, 552-567. (in Chinese with English abstract) [蒋 志刚, 李立立, 罗振华, 汤宋华, 李春旺, 胡慧建, 马勇, 吴毅, 王应祥, 周开亚, 刘少英, 冯祚建, 蔡蕾, 蔵春金金, 曾岩, 孟智斌, 平晓鸽, 方红霞 (2016) 通过红色名录评 估研究中国哺乳动物受威胁现状及其原因. 生物多样性, 24, 552-567.]

Kerr JT, Packer L (1997) Habitat heterogeneity as a determinant of mammal species richness in high-energy regions. Nature, 385, 252-254.

Kissling WD, Carl G (2008) Spatial autocorrelation and the selection of simultaneous autoregressive models. Global Ecology and Biogeography, 17, 59-71.

Kreft H, Jetz W (2007) Global patterns and determinants of vascular plant diversity. Proceedings of the National Academy of Sciences, USA, 104, 5925-5930.

Legendre P, Legendre L (1998) Numerical Ecology. Elsevier, Amsterdam.

Li LP, Wang ZH, Zerbe S, Abdusalih N, Tang ZY, Ma M, Yin
LK, Mohammat A, Han WX, Fang JY (2013) Species richness patterns and water-energy dynamics in the drylands of northwest China. PLoS ONE, 8, e66450.

Lin X, Wang ZH, Tang ZY, Zhao SQ, Fang JY (2009) Geographic patterns and environmental correlates of terrestrial mammal species richness in China. Biodiversity Science, 17, 652-663. (in Chinese with English abstract) [林 金金, 王志恒, 唐志尧, 赵淑清, 方精云 (2009) 中国陆栖 哺乳动物物种丰富度的地理格局及其与环境因子的关系. 生物多样性, 17, 652-663.]

Lu LM, Mao LF, Yang T, Ye JF, Liu B, Li HL, Sun M, Miller JT, Mathews S, Hu HH, Niu YT, Peng DX, Chen YH, Smith SA, Chen M, Xiang KL, Le CT, Dang VC, Lu AM, Soltis PS, Soltis DE, Li JH, Chen ZD (2018) Evolutionary history of the angiosperm flora of China. Nature, 554, 234-238.

Luck GW (2007) A review of the relationships between human population density and biodiversity. Biological Reviews, 82, 607-645.

Moeslund JE, Arge L, Bøcher PK, Dalgaard T, Svenning JC (2013) Topography as a driver of local terrestrial vascular plant diversity patterns. Nordic Journal of Botany, 31, 129-144.

Newbold T, Hudson LN, Hill SLL, Contu S, Lysenko I, Senior RA, Börger L, Bennett DJ, Choimes A, Collen B, Day J, de Palma A, Díaz S, Echeverria-Londoño S, Edgar MJ, Feldman A, Garon M, Harrison MLK, Alhusseini T, Ingram DJ, Itescu Y, Kattge J, Kemp V, Kirkpatrick L, Kleyer M, Correia DLP, Martin CD, Shai MR, Novosolov M, Yuan P, Phillips HRP, Purves DW, Robinson A, Simpson J, Tuck SL, Weiher E, White HJ, Ewers RM, Mace GM, Scharlemann JPW, Purvis A (2015) Global effects of land use on local terrestrial biodiversity. Nature, 520, 45-50.

O’Brien EM, Field R, Whittaker RJ (2000) Climatic gradients in woody plant (tree and shrub) diversity: Water-energy dynamics, residual variation, and topography. Oikos, 89, 588-600.

O’Brien EM (1998) Water-energy dynamics, climate, and prediction of woody plant species richness: An interim general model. Journal of Biogeography, 25, 379-398.

Qian H (2013) Environmental determinants of woody plant diversity at a regional scale in China. PLoS ONE, 8, e75832.

R Core Team (2019) R: A Language and Environment for Statistical Computing. https://www.R-project.org/. (accessed on 2019-09-01)

Ricklefs RE (1987) Community diversity: Relative roles of local and regional processes. Science, 235, 167-171.

Sarr DA, Hibbs DE, Huston MA (2005) A hierarchical perspective of plant diversity. Quarterly Review of Biology, 80, 187-212.

Shmida A, Wilson MV (1985) Biological determinants of species-diversity. Journal of Biogeography, 12, 1-20.

Simard M, Pinto N, Fisher JB, Baccini A (2011) Mapping forest canopy height globally with spaceborne lidar. Journal 
of Geophysical Research: Biogeosciences, 116, 1-12.

Stein A, Gerstner K, Kreft H (2014) Environmental heterogeneity as a universal driver of species richness across taxa, biomes and spatial scales. Ecology Letters, 17, 866-880.

Stein A, Kreft H (2015) Terminology and quantification of environmental heterogeneity in species-richness research. Biological Reviews, 90, 815-836.

Svenning JC, Skov F (2007) Ice age legacies in the geographical distribution of tree species richness in Europe. Global Ecology and Biogeography, 16, 234-245.

Tittensor DP, Walpole M, Hill SLL, Boyce DG, Britten GL, Burgess ND, Butchart SHM, Leadley PW, Regan EC, Alkemade R, Baumung R, Bellard C, Bouwman L, Bowles-Newark NJ, Chenery AM, Cheung WWL, Christensen V, Cooper HD, Crowther AR, Dixon MJR, Galli A, Gaveau V, Gregory RD, Gutierrez NL, Hirsch TL, Höft R, Januchowski-Hartley SR, Karmann M, Krug CB, Leverington FJ, Loh J, Lojenga RK, Malsch K, Marques A, Morgan DHW, Mumby PJ, Newbold T, Noonan-Mooney K, Pagad SN, Parks BC, Pereira HM, Robertson T, Rondinini C, Santini L, Scharlemann JPW, Schindler S, Sumaila UR, Teh LSL, van Kolck J, Visconti P, Ye YM (2014) A mid-term analysis of progress toward international biodiversity targets. Science, 346, 241-244.

Vitousek PM, Mooney HA, Lubchenco J, Melillo JM (1997) Human domination of Earth's ecosystems. Science, 277, 494-499.

Wang ZH, Fang JY, Tang ZY, Lin X (2011) Patterns, determinants and models of woody plant diversity in China. Proceedings of the Royal Society B: Biological Sciences, 278, 2122-2132.

Xing YW, Ree RH (2017) Uplift-driven diversification in the Hengduan Mountains, a temperate biodiversity hotspot. Proceedings of the National Academy of Sciences, USA, 114, E3444-E3451.

Xu C, Huang ZYX, Chi T, Chen BJW, Zhang MJ, Liu MS (2014) Can local landscape attributes explain species richness patterns at macroecological scales? Global Ecology and Biogeography, 23, 436-445.

Xu HG, Cao MC, Wu Y, Cai L, Cao Y, Wu J, Lei JC, Le ZF, Ding H, Cui P (2016) Disentangling the determinants of species richness of vascular plants and mammals from national to regional scales. Scientific Reports, 6, 21988.

Zhang ZD, Yu YW, Hua LM, Pu X, Wang HC, Liang TG (2014) Analysis of the distribution pattern of wild vascular plant diversity in Gansu Province, China. Acta Prataculturae Sinica, 23, 22-30. (in Chinese with English abstract) [ 张志 达, 于应文, 花立民, 蒲训, 王虎成, 梁天刚 (2014) 甘 肃省野生维管植物多样性分布格局分析. 草业学报, 23, 22-30.]

Zhao SQ, Fang JY, Peng CH, Tang ZY (2006) Relationships between species richness of vascular plants and terrestrial vertebrates in China: Analyses based on data of nature reserves. Diversity and Distributions, 12, 189-194.

(责任编委: 王志恒 责任编辑: 周玉荣) 